Article

\title{
A Role of Exopolysaccharide Produced by Streptococcus thermophilus in the Intestinal Inflammation and Mucosal Barrier in Caco-2 Monolayer and Dextran Sulphate Sodium-Induced Experimental Murine Colitis
}

\author{
Yun Chen ${ }^{1}$, Ming Zhang ${ }^{2, *(1)}$ and Fazheng Ren ${ }^{1}$ \\ 1 Key Laboratory of Functional Dairy, College of Food Science and Nutritional Engineering, China \\ Agricultural University, Beijing 100083, China; chenyun2018MN@163.com (Y.C.); \\ renfz2018fd1@163.com (F.R.) \\ 2 School of Food and Chemical Engineering, Beijing Technology and Business University, \\ Beijing 100048, China \\ * Correspondence: zhangming@th.btbu.edu.cn; Tel.: +86-10-62738589
}

Academic Editor: Chi-Fai Chau

Received: 27 December 2018; Accepted: 30 January 2019; Published: 31 January 2019

\begin{abstract}
Exopolysaccharide (EPS) produced by probiotics may play an important role in gastrointestinal disease prevention, including ulcerative colitis. However, there is no literature reporting on the intervention effects of purified EPS. The aim of this study was to investigate the alleviating effect of the purified EPS produced by Streptococcus thermophilus MN-BM-A01 on murine model of colitis induced by dextran sulphate sodium (DSS). A water-soluble heteropolysaccharide (EPS-1) isolated from MN-BM-A01 was composed of rhamnose, glucose, galactose, and mannose in a molar ratio of 12.9:26.0:60.9:0.25, with molecular weight of $4.23 \times 10^{5}$ Da. After EPS-1 administration, the disease severity of mouse colitis was significantly alleviated, mainly manifesting as the decrease of disease activity index and mitigated colonic epithelial cell injury. Meanwhile, pro-inflammatory cytokines levels (tumor necrosis factor- $\alpha$, interleukin-6, and interferon- $\gamma$ ) were significantly suppressed, the reduced expressions of tight junction protein (claudin-1, occludin, and E-canherin) were counteracted. In addition, the results in vitro showed that EPS-1 protected intestinal barrier integrity from the disruption by lipopolysaccharide in Caco-2 monolayer, increased expression of tight junction and alleviated pro-inflammatory response. Collectively, our study confirmed the protective effects of purified EPS produced by Streptococcus thermophilus on acute colitis via alleviating intestinal inflammation and improving mucosal barrier function.
\end{abstract}

Keywords: Streptococcus thermophiles; exopolysaccharide; DSS-induced colitis; tight junction protein

\section{Introduction}

Ulcerative colitis (UC) is a set of complicated chronic inflammatory and ulceration conditions of the colonic mucosa, accompanied by clinical symptoms such as diarrhea, rectal bleeding, body weight loss, and abdominal pain [1]. According to clinical observation, UC is easy to relapse and difficult to permanently cure. Epidemiological data revealed that the incidence of UC has been significantly increasing over the past two decades [2]. A lack of effective strategy was the most important cause of high morbidity. Therefore, finding a proper treatment is necessary.

While the precise mechanism of UC is still unclear, there is no doubt that intestinal mucosal barrier dysregulation and increased paracellular permeability play a critical role in the pathogenesis of 
UC [3]. Tight junctions (TJ) of enterocyte regulates the integrity of intestinal barrier predominantly, which influence the paracellular and transcellular transport [4]. Various transmembrane proteins including claudins, occludin and Zonula Occludens-1 (ZO-1) often considered to regulate intestinal permeability [5]. Many researches pointed out that, in UC patients, downregulations of tight junctions giving rise to the invasion of the colon wall with intestinal pathogens and toxins, which was considered as a vital event in the pathogenesis of intestinal inflammation [6-8]. While the molecular mechanisms that mediate the decreased expression of TJ proteins remain poorly characterized, increased production of pro-inflammatory cytokines, such as tumor necrosis factor (TNF)- $\alpha$ and interferon (IFN) $-\gamma$ was considered as the major upstream event leading to the disruption of the gut barrier [5,9]. These cytokines could alter the structure of the TJ by inducing the expression and activity of the Myosin Light Chain Kinase and/or triggering the endocytosis of TJ proteins [10]. In addition, anti-inflammatory cytokines (marked by upregulation of interleukin (IL)-13, IL-4, and IL-10) have been shown to be directly involved in the epithelial barrier function $[9,11]$. The emerging novel biological therapies targeting pro-inflammatory and anti-inflammatory cytokines balance were also reported $[12,13]$.

Recently, increasingly evidences supported that probiotic supply beneficial effects for host health, especially in terms of intestinal function improvement and prevention of a variety of intestinal diseases including UC $[14,15]$. In these reports, exopolysaccharides (EPSs) was often considered as one of the proposed mechanisms mediating (some of) these health benefits, because they aid in adherence and colonization within the human host $[16,17]$. On this basis, EPS also may act as intermediaries in the cross-talk between mammalian hosts and probiotic bacteria, interacted with receptors located in the gut epithelium [18], and are involved in the regulation of the host immune system [19]. Neriman Sengul et al. have showed that EPS-producing probiotic bacteria significantly attenuate experimental colitis by anti-oxidative stress [20]. Claudio Hidalgo et al. also showed that EPS-producing strains of B. animalis subsp. lactis could be a good candidate to check its anti-inflammatory ability in patients suffering from intestinal inflammation [21]. However, there is no literature reporting on the intervention effects of purified EPS in experimental colitis.

MN-BM-A01 (CGMCC No. 11383) was is a Streptococcus thermophiles (S. thermophilus) strain isolated from Yogurt Block in Gansu, China. S. thermophilus MN-BM-A01 could produce a high level of EPS, which can confer the yogurt with improved rheological properties, the maximum yield of EPS produced by MN-BM-A01 strains could reach $20.50 \mathrm{mg} / \mathrm{L}$. The genomic sequence indicated that this strain included a 35.3-kb gene cluster involved in EPS biosynthesis [22]. However, its biological function of EPS from this strain was unclear. The aim of this study was to investigate the alleviating effect and the possible mechanisms of the purified EPS on the murine model of colitis induced by dextran sulphate sodium (DSS).

\section{Results}

\subsection{The Molecular Mass and Monosaccharide Composition of the EPS}

The crude EPS from the culture supernatant of MN-BM-A01 was first prepared by protein removal and ethanol precipitation. By anion-exchange chromatography of DEAE Sepharose Fast flow, the crude EPS was separated into three main fractions, namely EPS-1, EPS-2, and EPS-3. A fraction profile was shown in Figure 1A. Sub-fraction EPS-1 was the main component, which classified as neutral polysaccharides according to its soluble characteristics.

The molecular mass of the EPS-1 was determined by gel-permeation chromatography (GPC, Figure 1B). The chromatogram of the EPS-1 appeared as a single symmetrical narrow peak, confirming the homogeneity of the purified EPS sample. The molecular mass was calculated as $423168.7\left(4.23 \times 10^{5}\right) \mathrm{Da}$, according to the standard curve equation $\log \mathrm{Mw}=-0.1741 \mathrm{x}+11.505$ $\left(R^{2}=0.9913\right)$, where Mw is the peak molecular weight and $x$ is the retention time. GC-MS analysis of the monosaccharide composition of the EPS-1 showed that the EPS was composed of different sugar 
monomers including rhamnose, glucose, galactose, and mannose in an approximate molar ratio of 12.9:26.0:60.9:0.25 (Figure 1C, Table 1), suggesting that the EPS-1 was a heteropolysaccharide.

Table 1. The monosaccharide composition of the EPS-1.

\begin{tabular}{ccccc}
\hline Sample NO. & Rhamnose (\%) & Glucose (\%) & Galactose (\%) & Mannose (\%) \\
\hline $\mathbf{1}$ & 12.5 & 25.8 & 61.4 & 0.25 \\
$\mathbf{2}$ & 13.4 & 26.1 & 60.2 & 0.23 \\
$\mathbf{3}$ & 12.7 & 26.0 & 61.1 & 0.27 \\
Average proportion & 12.9 & 26.0 & 60.9 & 0.25 \\
Standard deviation & 0.5 & 0.2 & 0.6 & 0.02 \\
\hline
\end{tabular}

A

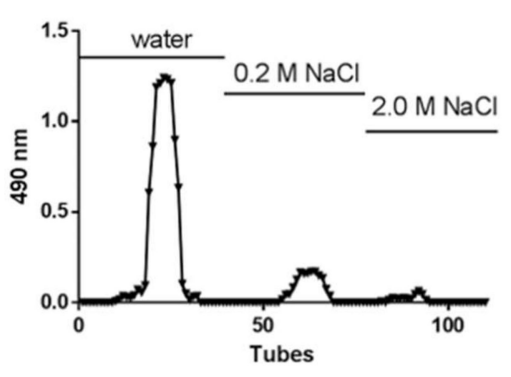

B

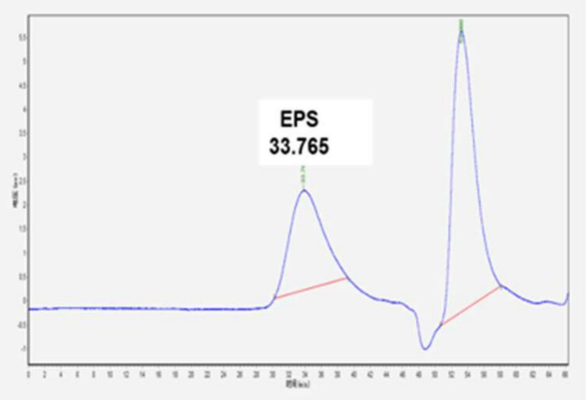

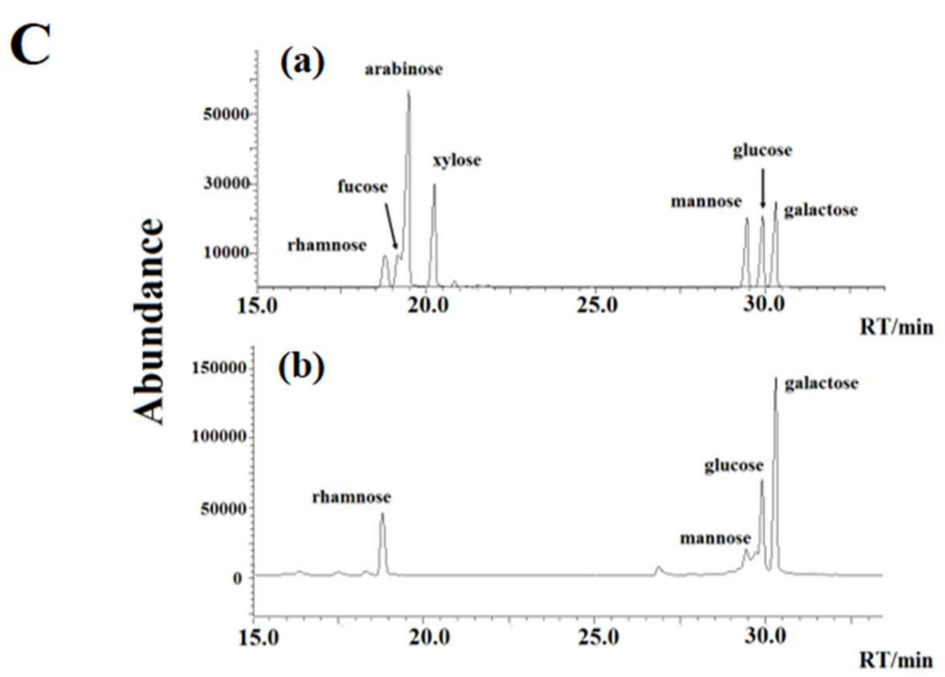

Figure 1. Isolation, molecular mass determination and monosaccharide composition of EPS from S. thermophilus MN-BM-A01. (A) Crude EPS separation profile by anion-exchange chromatography of DEAE Sepharose Fast flow. (B) GPC chromatogram of EPS-1. (C) Chromatogram of standard monosaccharides (a) and EPS-1 from S. thermophilus MN-BM-A01 monosaccharides (b) on chromatographic column.

\subsection{EPS-1 Alleviated the Clinical Symptoms of DSS-Induced Colitis in Mice}

There were no significant differences in body weight between the treatment groups at the beginning of the experiment $(p>0.05)$. When mice were treated with DSS for seven consecutive days, body weight was reduced by $11.6 \%$ compared to the control group (Figure 2A). Colon length is an important indicator of the incidence of colitis. DSS treatment shortened colon length by $23.3 \%$ $(p<0.05)$. EPS-1 $(200 \mathrm{mg} / \mathrm{kg})$ significantly alleviated the effects of DSS on body weight loss and colon shortening (Figure 2A,B).

The grade of ulcerative colitis induced by DSS was evaluated by the disease activity index (DAI) score, which was the sum of scores given for body weight loss, stool consistency, and presence of 
fecal blood. DAI scores in the four groups of mice are shown in Figure 2C. A significant increase of DAI score was observed in the DSS-treated group compared with the control groups $(p<0.05)$. In two EPS-1 treatment groups, the DAI scores were significantly decreased when compared to the DSS group $(p<0.05)$, indicating that EPS-1 could significantly alleviate the clinical symptoms of DSS-induced colitis in mice.

Histologic examination of the colon revealed epithelial injury and the degree of inflammation. The colons from all of the mice in each group were examined in hematoxylin-eosin (HE) stained slides. According to Figure 2E, DSS-only treated mice displayed the most severe infiltration of inflammatory cells, disruption of surface epithelium, and loss of crypts. Oral EPS-1 administration groups showed less severe colitis compared to the DSS-only treated group, but they were more severe when compared to the control group. Histological scores in the four groups of mice are shown in Figure 2D. At the end of the experiment (day 14), histological scores were determined. The histological scores in DSS-treated group increased compared to the control group. When EPS-1 was given for the whole experimental period, the decrease of the histological scores were remarkable, while it was still higher when compared to the control group $(p<0.05)$.
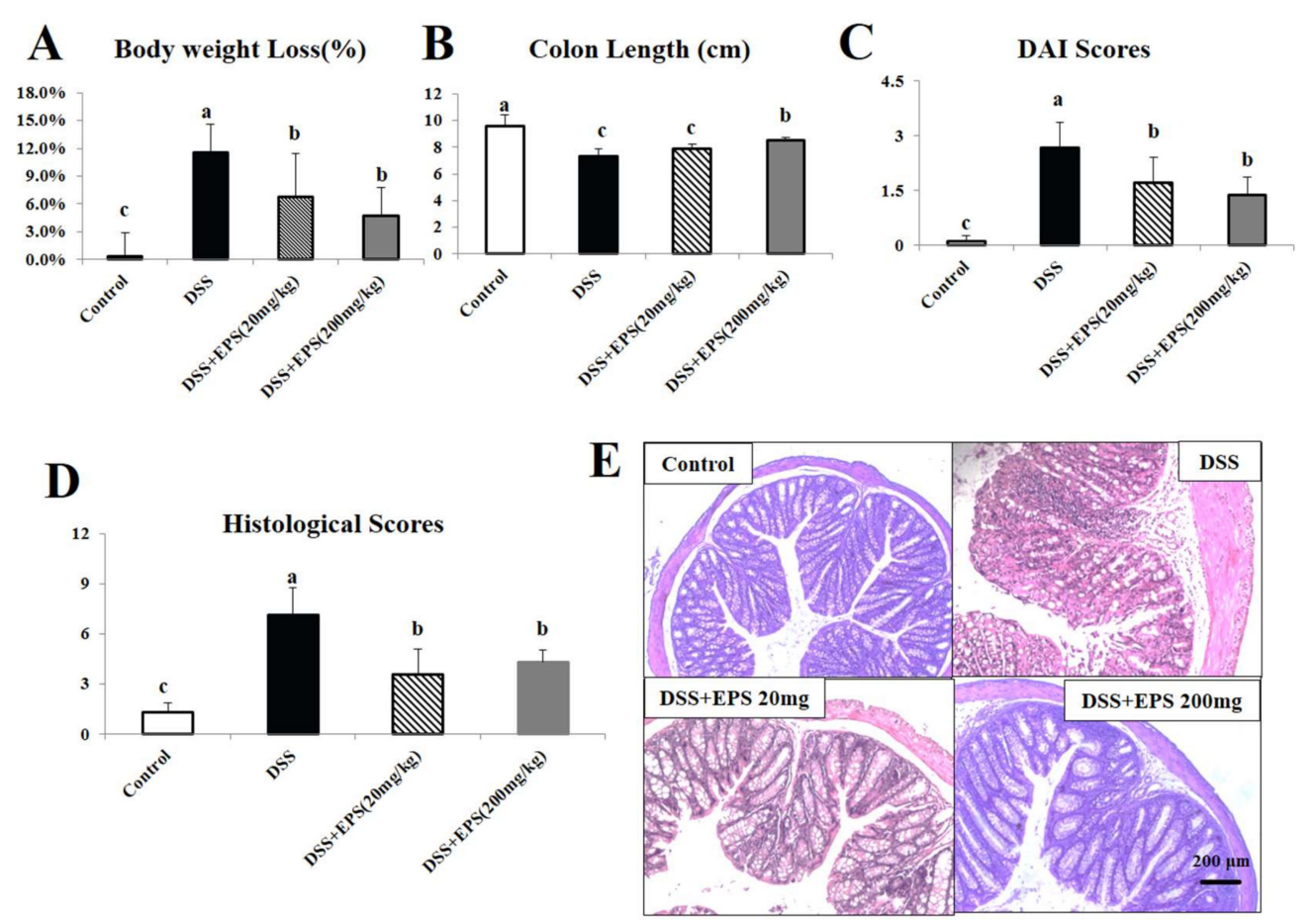

Figure 2. EPS-1 attenuates DSS-induced acute murine colitis. (A) Body weights loss, (B) variations of colon length, (C) disease activity index (DAI), and (D) histological scores of mice from each treatment group. (E) Representative HE staining colonic tissue from each treatment group, scale bars, $200 \mu \mathrm{m}$. Values with different superscript letters (a, b, c, d) are significantly different $(p<0.05)$.

\subsection{EPS-1 Promoted a Change in Pro-Inflammatory and Anti-Inflammatory Cytokines}

The DSS-induced colitis was accompanied by the imbalance of pro-inflammatory and anti-inflammatory cytokines, which was usually regarded as major suspects in the formation of colitis. To understand the mechanism that underlies the alleviation of DSS-induced colitis in mice after treatment with EPS-1, we examined the levels of Th1 pro-inflammatory (TNF- $\alpha$, IL-6, and IFN- $\gamma$ ) and anti-inflammatory (IL-4 and IL-10) in colon tissues. As shown in Figure 3A, in DSS treatment group, the expression of the IFN- $\gamma$, IL- 6 and TNF- $\alpha$ in colon tissues was significantly increased $(p<0.05)$. When EPS-1 was given for the whole experimental period, a remarkable decrease of the pro-inflammatory cytokine secretion (IFN- $\gamma$, IL-6, and TNF- $\alpha$ ) was observed $(p<0.05)$. In addition, 
the expression of anti-inflammatory cytokines were also detected in the colon tissues of all mice. As shown in Figure 3B, although IL-4 and IL-10 levels varied slightly after treatment with DSS and/or EPS-1, the difference was not significant when compared with the control group $(p<0.05)$.
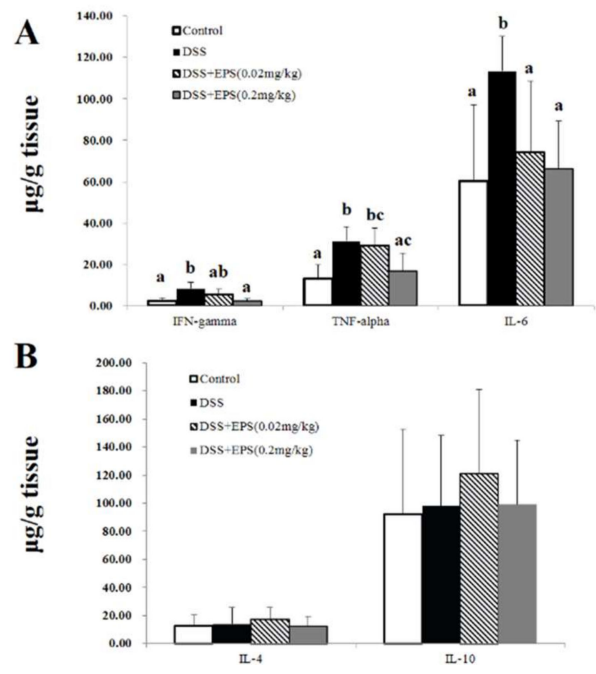

Figure 3. EPS-1 promoted a change in pro-inflammatory and anti-inflammatory cytokines. (A) The levels of pro-inflammatory cytokines in the colonic tissues from each treatment group. (B) The levels of anti-inflammatory cytokines in the colonic tissues from each treatment group. Values with different superscript letters $(\mathrm{a}, \mathrm{b}, \mathrm{c})$ are significantly different $(p<0.05)$.

\subsection{EPS-1 Relieved DSS-Induced Colonic Epithelial Tight Junction Disruption in Mice}

Tight junction (TJ) is an essential permeable intercellular barrier and plays a critical role in the intestinal epithelial barrier integrity. As shown in Figure 4, we observed that the expressions of tight junction proteins, such as claudin-1, occludin, and E-cadherin remarkably reduced in the colonic tissues of DSS induced colitis mice by Western-Blot. After EPS-1 administration, the reduced expressions of claudin-1, occludin, and E-canherin proteins were counteracted (Figure 4A,B), which provided another powerful evidence for the protective effects of EPS-1 on mice colitis.

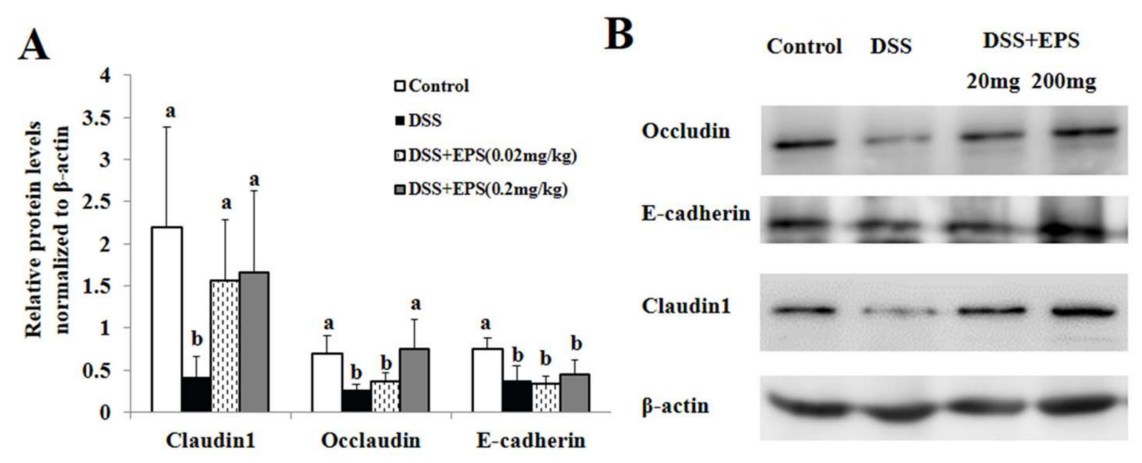

Figure 4. EPS-1 Relieved DSS-Induced Colonic Epithelial Tight Junction Disruption in Mice. (A) Relative protein levels of Occludin, E-cadherin and Claudin1 in the colon tissues normalized to $\beta$-actin. (B) Protein expression of Occludin, E-cadherin, and Claudin-1 in the colon tissues were analyzed by Western blot. Values with different superscript letters $(a, b$,$) are significantly different$ $(p<0.05)$.

\subsection{EPS-1 Protected against Colonic Epithelial Tight Junction Disruption In Vitro}

In order to further explicit the protective effects of EPS-1 on acute colitis, the continuous line of human epithelial colorectal adenocarcinoma, Caco-2 cell line was employed to carry out the in vitro experiment. Firstly, we tested the transepithelial electrical resistance (TER) values of Caco-2 
monolayers treated with lipopolysaccharide (LPS, $10 \mu \mathrm{g} / \mathrm{mL})$ without or with EPS-1 $(2 \mathrm{mg} / \mathrm{mL}$ ) and EPS-1 $(2 \mathrm{mg} / \mathrm{mL}$ ) alone for $24 \mathrm{~h}$. Compared with the no treatment cells (Control), as shown in Figure 5A, LPS caused a remarkable decrease of the TER levels after $24 \mathrm{~h}$. By contrast, EPS- 1 significantly dampened the LPS-induced drop of TER. Fluorescein isothiocyanate (FITC)-dextran measurement in the Caco- 2 monolayers showed $77.8 \%$ increase in the intensity of $4 \mathrm{kDa}$ FITC-dextran in the lower chamber of the Transwell cell cultures compared to the controls $(p<0.05)$. This improvement was counteracted significantly to $120.5 \pm 21.9 \%$ of the control by treatment with EPS- 1 ( $p<0.05$; Figure $5 \mathrm{~B}$ ). Consistent with the changes of TER and FITC-dextran measurement, as presented in Figure 5D,E, the expression of E-cadherin, occludin, and claudin-1 decreased in LPS group. EPS-1 remarkably alleviated the morphological disturbances of E-cadherin and claudin-1. These results suggest that EPS-1 protect intestinal barrier function from the disruption by LPS in Caco-2 monolayers.

To confirm if EPS-1 has an effect on inflammatory immune responses, we tested the levels of pro-inflammatory cytokines secreted by Caco-2 monolayers treated with LPS without or with EPS-1 for $24 \mathrm{~h}$. As demonstrated in Figure 5C, the levels of pro-inflammatory cytokines (TNF- $\alpha$, IFN- $\gamma$, and IL-6) significantly increased after treatment of LPS, a typical inflammatory activator. In contrast, consistent with the results of animal experiments, EPS-1 diminished the LPS-induced increase of pro-inflammatory cytokines $(p<0.05)$.

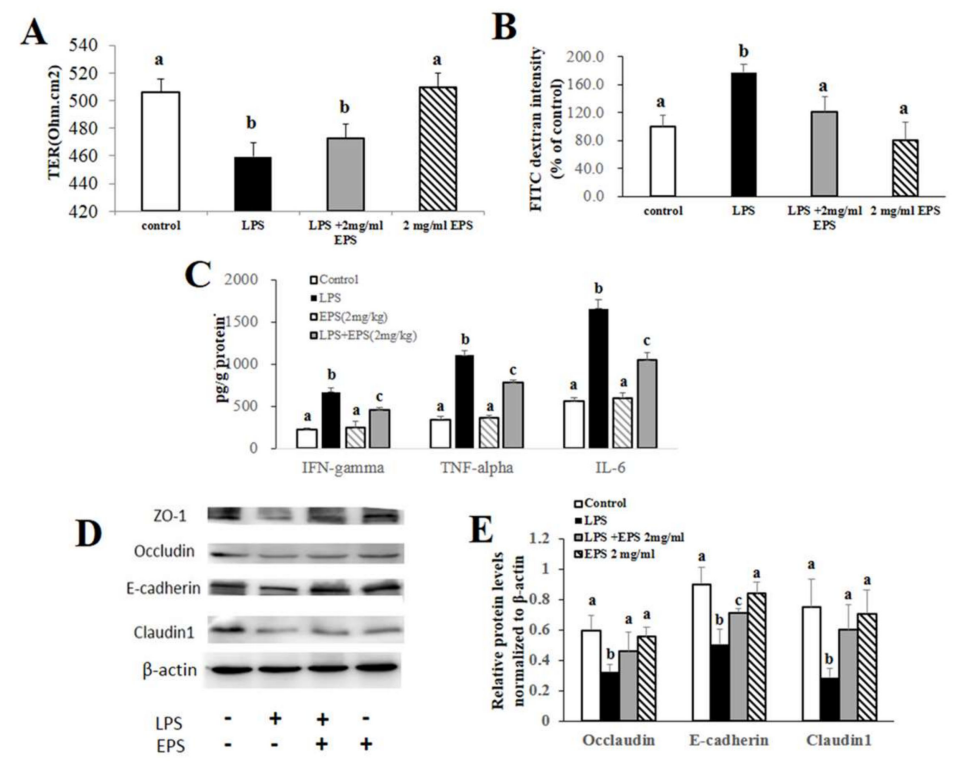

Figure 5. EPS-1 Protected intestinal barrier integrity from the disruption by LPS in Caco-2 monolayer. (A) The changes of transepithelial electrical resistance (TER) before and after treatment with LPS $(10 \mu \mathrm{g} / \mathrm{mL})$ and/or EPS-1 $(2 \mathrm{mg} / \mathrm{mL})$ for $24 \mathrm{~h}$ in Caco-2 monolayer. (B) FITC-dextran (4 kDa) permeability measurement in 21-day cultured Caco-2 monolayer after LPS and/or EPS-1 treatment. (C) The levels of pro-inflammatory cytokines in the Caco-2 cells from each treatment group. (D) Protein expression of Occludin, E-cadherin and Claudin1 in the Caco-2 cells from each treatment group. (E) Relative protein levels of Occludin, E-cadherin and Claudin1 in Caco-2 cells normalized to $\beta$-actin. Values with different superscript letters $(a, b, c)$ are significantly different $(p<0.05)$.

\section{Discussion}

Ulcerative colitis (UC) is a set of complicated chronic inflammatory and ulceration conditions of the colonic mucosa, accompanied by clinical symptoms [23]. Recently, increasingly, evidences supported that probiotics conferred a lot of health benefits, including UC prevention [15]. EPS may play a role in this prevention process [16]. However, there is no literature reporting on the intervention effects of purified EPS in experimental colitis. In this study, we verified that exopolysaccharide produced by $S$. thermophilus could alleviate the dextran sulfate sodium-induced experimental colitis 
in mice. The reduced severity of the disease after EPS treatment was associated with an inhibition of pro-inflammatory cytokine in the lymphocytes of colon. Furthermore, we identified that intestinal barrier function was significantly ameliorated in mice and Caco-2 monolayers after EPS treatment compared to the non-treated control mice.

S. thermophilus is the most important dairy starter. The exopolysaccharides of $S$. thermophilus can improve the properties of the dairy product and confer benefcial health effects [24]. Some studies indicated that EPS structure is very diverse, and has a close relationship with its functions $[25,26]$. Most S. thermophilus EPSs are heteropolysaccharide [27], which were composed of repeating subunits of three-eight different monosaccharides, and were predominantly composed of galactose, glucose, rhamnose, and $N$-acetyl-galactosamine in different ratios [28]. In this study, the EPS-1 produced by $S$. thermophilus MN-BM-A01 was a representative heteropolysaccharide, consisting of rhamnose, glucose, galactose, and mannose in an approximate molar ratio of 12.9:26.0:60.9:0.25.

The occurrence and development of UC were strongly associated with the imbalance of pro-inflammatory and anti-inflammatory cytokines [12]. A previous report showed that a UC-like mouse model of DSS-induced colitis had neutrophil accumulation and increased expression of pro-inflammatory in the colon [29]. TNF- $\alpha$, a very potent matrix metalloproteinases produced by neutrophils and activated macrophages contribute to the epithelial ulceration and sub-mucosal destruction [30]. Progressive release of cytokines IFN- $\gamma$ and IL-6 from inflamed colon, produced by $T$ cells and macrophages was also shown to be correlated with development of colitis. Administration of a neutralization antibody against IFN- $\gamma$ significantly ameliorated colonic inflammation in DSS-induced colitis in mice, and IFN- $\gamma-/$-mice [31,32]. Taken together, the release of pro-inflammatory cytokines in this acute colitis model is the result of rapid recruitment and activity of macrophages and neutrophils and initiating lymphocyte proliferation and activity [33,34]. Our study also demonstrated that production of pro-inflammatory cytokines increased significantly, but anti-inflammatory cytokines (IL-4 and IL-10) varied slightly in UC mice.

Inhibition of pro-inflammatory cytokines has been used as a major strategy to attenuate colitis. Although therapeutic effects of probiotics on colitis were strain-specific and dose-dependant, the anti-inflammatory effects of probiotics play a decisive role $[35,36]$. A previous study has indicated that the expression of TNF- $\alpha$, IL- $1 \beta$, and IL- 6 in the colon tissues was diminished dose-dependently by a mixture of three potential probiotic strains (Lactobacillus johnsonii IDCC9203, Lactobacillus plantarum IDCC3501, and Bifidobacterium animalis subspecies lactis IDCC4301) in DSS induced colitis [37]. Pan, T. et al. also illustrated that an appropriate dose of Lactobacillus paracasei subsp. paracasei LC-01 can prevent intestinal damage in mice with DSS-induced colitis by inhibiting the expression of inflammatory cytokines [38]. In our study, EPS- 1 treatment attenuated the release of TNF- $\alpha$, IFN- $\gamma$ and IL-6 significantly, suggesting that this effect is the primary cause of anti-colitic activity of EPS. The inhibition effect or pro-inflammatory cytokines was further confirmed in Caco-2 cell lines treated by LPS, with or without EPS-1. Results demonstrated that EPS-1 attenuated the LPS-induced inflammatory response of the mucosa and the TER reduction, accompanying significantly alleviated morphological disruption of tight junction protein.

In this study, the expression of TNF- $\alpha$, IFN- $\gamma$, and IL- 6 in the colon tissues and Caco-2 monolayer were diminished dose-dependently by administrations of EPS-1, consistent with the reduction of DAI and histopathological scores. These results suggested that EPS-1 improved the imbalance of pro-inflammatory and anti-inflammatory cytokines in rat intestinal mucosa, and promoted self-repair of intestinal mucosa. In addition, pro-inflammatory cytokines, such as tumor necrosis factor TNF- $\alpha$ and IFN- $\gamma$ cause dysregulation of barrier permeability during inflammation [3]. This underlying mechanism of the anti-inflammatory effect of EPS would be studied further.

Tight junction destruction plays a key role in the development and progression of inflammatory bowl disease (IBD) [39]. In previous animal experiment, it has been found that the congenital epithelial cell tight junction protein knockout mice appeared with intestinal pathological changes that were similar with that of IBD after birth, implying that TJ proteins were involved in the pathogenesis of 
IBD [40]. Various molecules, such as claudins, occludin, and E-canherin, are involved in maintaining this barrier [41,42]. However, loss of barrier integrity, initiated by bacteria or by treatment with a chemical, such as LPS, results in bacterial invasion and inflammation. A large number of studies have shown that restoring and maintaining intestinal mucosal barrier function were beneficial to improve the defensive function of intestinal mucosa, promote disease remission, and reduce relapse times of IBD $[43,44]$. Recently, Zhou X et al. found that EPS produced by Lactobacillus plantarum promoted epithelial barrier function and the expression of TJ protein and suggested that the regulation of the epithelial barrier function should be STAT3 dependent, which led to upregulation of Occludin and ZO-1 in the intestinal epithelial cells [45]. Our data also revealed that EPS-1 could improve the gut barrier function in vitro and in vivo and increased the expression of tight junction proteins. The specific mechanism of these actions need further study.

\section{Materials and Methods}

\subsection{Isolation and Purification of EPS}

The S. thermophilus MN-BM-A01 was cultured in $12 \mathrm{~g} / 100 \mathrm{~mL}$ skimmed milk at $37{ }^{\circ} \mathrm{C}$ for $24 \mathrm{~h}$. After incubation, the EPS was isolated and purified as previously described [46]. Briefly, trichloroacetic acid was added to the culture to a final concentration of $4 \mathrm{~g} / 100 \mathrm{~mL}$, and the mixture was stirred for $30 \mathrm{~min}$ at room temperature. Cells and precipitated proteins were removed by centrifugation $(8000 \times g$, $\left.4{ }^{\circ} \mathrm{C}, 10 \mathrm{~min}\right)$. Crude EPS was precipitated from the supernatant by addition of two volumes of cold ethanol overnight at $4{ }^{\circ} \mathrm{C}$, and then collected by centrifugation at $8000 \times g$ for $10 \mathrm{~min}$ and dissolved in distilled water $(50 \mathrm{~g} / 100 \mathrm{~mL})$. The solution was dialyzed using a dialysis bag (Mw cut-off $8 \mathrm{kDa}$ to $14 \mathrm{kDa}$ ) against distilled water for $48 \mathrm{~h}$ at $4{ }^{\circ} \mathrm{C}$ with water replacement thrice a day.

The crude EPS solution $(0.2 \mathrm{~g} / \mathrm{mL}, 10 \mathrm{~mL})$ was fractionated with an anion exchange chromatography on a DEAE-FAST-FLOW column $(50 \times 500 \mathrm{~mm})$, eluted with deionized water, $0.2 \mathrm{M}$, and $0.5 \mathrm{M} \mathrm{NaCl}$ solution at a flow rate of $1 \mathrm{~mL} / \mathrm{min}$. Every $5 \mathrm{~mL}$ of elution was collected automatically and the carbohydrate content was determined by phenol-sulfuric acid method. Peak fractions containing polysaccharides were pooled, dialyzed, and lyophilized. The purified EPS-1 solution $(10 \mathrm{~g} / \mathrm{mL}, 10 \mathrm{~mL})$ was performed by an automatic polysaccharide gel purification system (Superdex 75 , GE Healthcare, Boston, MA, USA) with column $(1.6 \times 80 \mathrm{~cm})$, eluted with $0.5 \% \mathrm{NaCl}$ solution at a flow rate of $0.2 \mathrm{~mL} / \mathrm{min}$. Every $2 \mathrm{~mL}$ of elution was collected automatically and the carbohydrate content was determined by the phenol-sulfuric acid method. Peak fractions containing polysaccharides were pooled, dialyzed, and lyophilized.

\subsection{Molecular Mass Determination of EPS}

The molecular mass of the purified EPS was measured by gel-permeation chromatography (GPC). The GPC system (Waters, Milford, MA, USA) consisted of three Waters Ultra-hydrogel 250, 1000 and 2000 $(7.8 \times 300 \mathrm{~mm})$ columns in series. The column was eluted with $20 \mathrm{mM} \mathrm{CH}_{3} \mathrm{COONH}_{4}$ solution at a flow rate of $0.5 \mathrm{~mL} / \mathrm{min}$, and the injection volume of sample was $20 \mu \mathrm{L}$ at an internal temperature of $40{ }^{\circ} \mathrm{C}$.

\subsection{Monosaccharide Analysis}

The EPS (2 mg) was hydrolyzed with $1 \mathrm{~mL}$ trifluoroacetic acid (2 M) for $1.5 \mathrm{~h}$. Excess trifluoroacetic acid was removed by rotary evaporation. The hydrolyzate was detected by GC-mass spectrometry (GC-MS) on a Hp-5 (Agilent Technology, Santa Clara, CA, USA) chromatographic column $(300 \times 0.25 \times 0.32 \mathrm{~mm})$ with hydrogen and air and helium at the flow rates of 30 and $400 \mathrm{~mL} / \mathrm{min}$, respectively, and helium was used as carrier gas at a flow rate of $1 \mathrm{~mL} / \mathrm{min}$. The standard sugars were rhamose, fucose, arabinose, xylose, mannose, glucose, and galactose. 


\subsection{Animals, Diets and Experimental Procedure.}

Forty 6-8 weeks old pathogen-free male BALB/c mice were obtained from Vital River Laboratory Animal Technology Co. (Beijing, China). The animals were maintained on a 12-h-dark-light cycle and allowed free access to a basal diet and tap water under controlled temperatures $\left(25 \pm 2{ }^{\circ} \mathrm{C}\right)$. All experimental protocols (LA2016285) were approved by the Ethics Committee of Peking University Health Science Center and were conducted in accordance with the Guide for the Care and Use of Laboratory Animals.

After two weeks quarantine, the mice were divided into four groups and each group consisted of 10 animals. Untreated (control) groups were given $0.2 \mathrm{~mL}$ distilled water and received tap water orally for 14 days. For inducing chronic colitis, the rats in DSS treatment were administrated with $2.5 \mathrm{~g} / 100 \mathrm{~mL}$ DSS (mol. wt $40 \mathrm{kD}$; TdB Consultancy, Uppsala, Sweden) in murine drinking water for seven days. A DSS alone group were given $0.2 \mathrm{~mL}$ distilled water from the day eight to 14 . To study the therapeutic effect of EPS-1, this substance $(20,200 \mathrm{mg} / \mathrm{kg}$ body weight once per day) was orally administered from day eight to 14 , respectively. Control mice were administered with PBS. Body weight loss was calculated as the percent difference between the original body weight and the actual body weight daily.

\subsection{Evaluation of Colitis}

In all animal daily weight, daily presence of gross blood, and daily stool consistency was determined. The DAI was determined by an investigator blinded to the protocol by scoring changes in weight, hemoccult positivity or gross bleeding, and stool consistency as the protocol previously described [47]. At the end of the experiment (day 14), after sacrificed, histological injury score of each colon was evaluated by morphological criteria as the protocol previously described [34]. The length of colons was measured and cut open longitudinally $1 \mathrm{~cm}$ of the distal colon for formalin fixing, paraffin embedding and HE staining. The paraffin sections of colon were graded by two blinded investigators with a range from zero to three as to the amount of inflammation (acute and chronic), depth of inflammation, and with a range from zero to four as to the amount of crypt damage or regeneration, as previously described [34]. The remaining colon tissue was used later to measure other tests.

\subsection{Cell Lines and Monolayer Preparation}

To investigate the effect of EPS on intestinal barrier dysfunction and pro-inflammatory cytokines, the Caco-2 cells were seeded on 24 well $12 \mathrm{~mm}$ polyester Transwell filters (Corning, Corning, NY, USA) with $0.4 \mu \mathrm{M}$ pore size at a concentration of $2 \times 10^{5}$ cells/Transwell. Caco- 2 cells were cultured in Dulbecco's Modified Eagle's medium (DMEM) supplemented with 10\% $(v / v)$ foetal bovine serum (FBS) and $1 \mathrm{~g} / 100 \mathrm{~mL}$ penicillin-streptomycin for 21 days. Caco-2 cells become a full monolayer with a mean TER exceeding $200 \Omega \cdot \mathrm{cm}^{2}$. Keep on culturing until the TER exceeded $400 \Omega \cdot \mathrm{cm}^{2}$ measured by a Millicell-Electrical Resistance System voltohmmeter (Millipore, Bedford, MA, USA) and the TER kept stable for three days until they formed a differentiated monolayer. For treatment, the Caco-2 cells were treated with LPS $(10 \mu \mathrm{g} / \mathrm{mL})$ without or with EPS-1 $(2 \mathrm{mg} / \mathrm{mL})$ for $24 \mathrm{~h}$. EPS-1 $(2 \mathrm{mg} / \mathrm{mL})$ was added to the apical chamber of Transwell supports. Then, transepithelial electrical resistance (TER) values of all monolayers were measured with Millicell-ERS voltohmmeter. To measure dextran permeability, fluorescein isothiocyanate (FITC) dextran $(4 \mathrm{kDa} ; 3 \mathrm{mg} / \mathrm{mL})$ was added to the upper chamber without medium change. Aliquots were withdrawn from the lower chambers after $4 \mathrm{~h}$ and assayed for fluorescence at $515 \mathrm{~nm}$ with excitation at $492 \mathrm{~nm}$.

\subsection{Measure of Cytokine Production in Colonic Mucosa and Cells}

Colonic mucosa was cut into pieces and homogenised in ice-cold $100 \mathrm{mM}$ Tris- $\mathrm{HCl}$ buffer, $\mathrm{pH}$ 7.0, containing a cocktail of protease inhibitors (Beyotime, Shanghai, China) and supplemented 
with $1 \mathrm{mM}$ phenylmethanesulfonyl fluoride. After $12,744 \times g$ centrifugation at $4{ }^{\circ} \mathrm{C}$ for $10 \mathrm{~min}$, the supernatant was collected and then quantified using bicinchoninic acid (BCA) protein assay reagent kit (Beyotime, Shanghai, China). The levels of TNF- $\alpha$, IFN- $\gamma$, IL-4, IL-6, and IL-10 were measured using the enzyme-linked immunosorbent assay kits (R\&D, Emeryville, CA, USA) according to the manufacturer's recommendations. Briefly, anti-mouse cytokine antibodies were used to capture the proteins in supernatant, biotinylated polyclonal antibodies were used for detection. Color changes were determined at $450 \mathrm{~nm}$. The amount of cytokines were determined based on the standard curve.

\subsection{Western Blot Analysis}

Colon tissues and Caco-2 cells were homogenated and lysed in lysis buffer supplemented with the protease and phosphatase inhibitor (PMSF, $0.5 \mathrm{mmol} / \mathrm{L}$ ). Briefly, $100 \mathrm{mg}$ tissue was homogenized in Radio Immunoprecipitation Assay (RIPA) lysis buffer (Beyotime) by using homogenizer. After homogenization, the supernatant was collected after a 5 min centrifugation at $17,346 \times g, 4{ }^{\circ} \mathrm{C}$. $4 \times 10^{5}$ Caco-2 cells were seeded in 6-Well Plate for $24 \mathrm{~h}$. Then treated with LPS $(10 \mu \mathrm{g} / \mathrm{mL})$ without or with EPS-1 (2 mg/mL) incubation for another $24 \mathrm{~h}$. The cells were then lysed and extracted protein with RIPA buffer by ultrasonication. Collected the supernatant by $12,744 \times g$ centrifugation, $4^{\circ} \mathrm{C}$, $10 \mathrm{~min}$. The protein concentration was determined using BCA protein assay reagent kit (Beyotime), then the concentration of each sample was unified and the lysates were mixed with $4 \times$ sodium dodecyl sulfonate (SDS) sample loading buffer and denatured in boiling water for $5 \mathrm{~min}$ to denature the protein and then separated by 10 15 g/100 mL SDS-PAGE. Then the proteins were electro-transferred to PVDF member at $200 \mathrm{~mA}$ for $2 \mathrm{~h}$. The membranes were incubated with primary antibodies: anti- $\beta$-actin (1:2500, Bioss, Beijing, China), Anti-Occludin (1:50,000, Abcam, Cambridge, MA, USA), anti-E-cadherin (1:1000, Abcam, USA), anti-Claudin1 (1:2000, Abcam, USA) for $12 \mathrm{~h}$ at $4{ }^{\circ} \mathrm{C}$. After 5 times washed with $0.1 \mathrm{~g} / 100 \mathrm{~mL}$ Tween-20 in PBS, then incubated with secondary antibodies (anti-rabbit and anti-mouse, 1:1000, Beyotime, Shanghai, China) for $1 \mathrm{~h}$ at room temperature. After being washed five times, the protein bands were visualized by ECL substrate (Millipore, Bedford, MA, USA) and Amersham Imager 600 (GE Healthcare, Boston, MA, USA). The density of the protein bands were quantified using Gel-pro software 4.0 (Media Cybernetics, Rockville, MD, USA) and $\beta$-actin was used as a control protein.

\subsection{Statistical Analysis}

All statistical analysis was done the statistical software Statistical Product and Service Solutions (version 19.0, SPSS Inc., Chicago, IL, USA) for Windows and results were expressed as mean \pm standard deviation. The statistical significance of the differences among the experimental groups was evaluated using analysis of variance test and unpaired Student's t-test. The level of statistical significance was defined as $p<0.05$.

\section{Conclusions}

In this study, a water-soluble exopolysaccharide, designated as EPS-1, was isolated from MN-BM-A01 and purified. EPS-1 was a heteropolysaccharide, which was composed of rhamnose, glucose, galactose and mannose in an approximate molar ratio of 12.9:26.0:60.9:0.25. Our study confirmed the protective effects of purified EPS-1 on acute mouse colitis, mainly manifesting as the decrease of DAI and mitigated colonic epithelial cell injury. The protective effects might be related to the alleviation of intestinal inflammation and the improvement of mucosal barrier function. Thus, EPS-1 may be a preventive therapeutic agent for UC and a new health care product for intestinal health.

Author Contributions: Y.C. performed the majority of experiments, data acquisitions, analyzed data, and wrote the manuscript. M.Z. contributed to analyze data, supervised the study and finalize the manuscript. F.R. designed the experiment and supervised the study. All authors reviewed the manuscript.

Funding: The research was supported by National Natural Science Foundation of China (31601443). 
Conflicts of Interest: The authors declare no conflict of interest.

\section{References}

1. Kaser, A.; Zeissig, S.; Blumberg, R.S. Inflammatory bowel disease. Annu. Rev. Immunol. 2010, $28,573-621$. [CrossRef] [PubMed]

2. Lakatos, P.L. Recent trends in the epidemiology of inflammatory bowel diseases: Up or down? World J. Gastroenterol. 2006, 12, 6102-6108. [CrossRef] [PubMed]

3. Lechuga, S.; Ivanov, A.I. Disruption of the epithelial barrier during intestinal inflammation: Quest for new molecules and mechanisms. Biochim. Biophys. Acta Mol. Cell Res. 2017, 1864, 1183-1194. [CrossRef] [PubMed]

4. Al-Sadi, R.; Boivin, M.; Ma, T. Mechanism of cytokine modulation of epithelial tight junction barrier. Front. Biosci. 2009, 14, 2765-2778. [CrossRef]

5. Barreau, F.; Hugot, J.P. Intestinal barrier dysfunction triggered by invasive bacteria. Curr. Opin. Microbiol. 2014, 17, 91-98. [CrossRef]

6. Suzuki, T. Regulation of intestinal epithelial permeability by tight junctions. Cell. Mol. Life Sci. 2013, 70, 631-659. [CrossRef]

7. Awad, W.A.; Hess, C.; Hess, M. Enteric pathogens and their toxin-induced disruption of the intestinal barrier through alteration of tight junctions inchickens. Toxins 2017, 9, 60. [CrossRef]

8. Ugalde-Silva, P.; Gonzalez-Lugo, O.; Navarro-Garcia, F. Tight Junction Disruption induced by type 3 secretion system effectors injected by enteropathogenic and enterohemorrhagic Escherichia coil. Front. Cell Infect. Microbiol. 2016, 6, 87. [CrossRef]

9. Kamada, N.; Hisamatsu, T.; Honda, H.; Kobayashi, T.; Chinen, H.; Takayama, T.; Kitazume, M.T.; Okamoto, S.; Koganei, K.; Sugita, A.; et al. TL1A produced by lamina propria macrophages induces Th1 and Th17 immune responses in cooperation with IL-23 in patients with Crohn's disease. Inflamm. Bowel Dis. 2010, 16, 568-575. [CrossRef]

10. Wang, F.; Graham, W.V.; Wang, Y.; Witkowski, E.D.; Schwarz, B.T.; Turner, J.R. Interferon-gamma and tumor necrosis factor-alpha synergize to induce intestinal epithelial barrier dysfunction by up-regulating myosin light chain kinase expression. Am. J. Pathol. 2005, 166, 409-419. [CrossRef]

11. Forland, D.T.; Johnson, E.; Saetre, L.; Lyberg, T.; Lygren, I.; Hetland, G. Effect of an extract based on the medicinal mushroom Agaricus blazei Murill on expression of cytokines and calprotectin in patients with ulcerative colitis and Crohn's disease. Scand. J. Immunol. 2011, 73, 66-75. [CrossRef] [PubMed]

12. Matsumura, K.; Nakase, H.; Yamamoto, S.; Yoshino, T.; Takeda, Y.; Kasahara, K.; Ueno, S.; Uza, N.; Chiba, T. Modulation of the Th1/Th2 balance by infliximab improves hyperthyroidism associated with a flare-up of ulcerative colitis. Inflamm. Bowel Dis. 2009, 15,967-968. [CrossRef] [PubMed]

13. Kurtovic, J.; Segal, I. Recent advances in biological therapy for inflammatory bowel disease. Trop. Gastroenterol. 2004, 25, 9-14. [PubMed]

14. De Oliveira, G.L.V.; Leite, A.Z.; Higuchi, B.S.; Gonzaga, M.I.; Mariano, V.S. Intestinal dysbiosis and probiotic applications in autoimmune diseases. Immunology 2017, 152, 1-12. [CrossRef] [PubMed]

15. Ohland, C.L.; MacNaughton, W.K. Probiotic bacteria and intestinal epithelial barrier function. Am. J. Physiol.-Gastrointest. Liver Physiol. 2010, 298, G807-G819. [CrossRef] [PubMed]

16. Fanning, S.; Hall, L.J.; Cronin, M.; Zomer, A.; MacSharry, J.; Goulding, D.; Motherway, M.O.; Shanahan, F.; Nally, K.; Dougan, G.; van Sinderen, D. Bifidobacterial surface-exopolysaccharide facilitates commensal-host interaction through immune modulation and pathogen protection. Proc. Natl. Acad. Sci. USA 2012, 109, 2108-2113. [CrossRef] [PubMed]

17. Conover, M.S.; Sloan, G.P.; Love, C.F.; Sukumar, N.; Deora, R. The Bps polysaccharide of Bordetella pertussis promotes colonization and biofilm formation in the nose by functioning as an adhesin. Mol. Microbiol. 2010, 77, 1439-1455. [CrossRef]

18. Lebeer, S.; Verhoeven, T.L.A.; Francius, G.; Schoofs, G.; Lambrichts, I.; Dufrene, Y.; Vanderleyden, J.; De Keersmaecker, S.C.J. Identification of a Gene Cluster for the Biosynthesis of a Long, Galactose-Rich Exopolysaccharide in Lactobacillus rhamnosus GG and Functional Analysis of the Priming Glycosyltransferase. Appl. Environ. Microb. 2009, 75, 3554-3563. [CrossRef] 
19. Xu, C.L.; Wang, Y.Z.; Jin, M.L.; Yang, X.Q. Preparation, characterization and immunomodulatory activity of selenium-enriched exopolysaccharide produced by bacterium Enterobacter cloacae Z0206. Bioresour. Technol. 2009, 100, 2095-2097. [CrossRef]

20. Sengul, N.; Isik, S.; Aslim, B.; Ucar, G.; Demirbag, A.E. The effect of exopolysaccharide-producing probiotic strains on gut oxidative damage in experimental colitis. Dig. Dis. Sci. 2011, 56, 707-714. [CrossRef]

21. Hidalgo-Cantabrana, C.; Algieri, F.; Rodriguez-Nogales, A.; Vezza, T.; Martinez-Camblor, P.; Margolles, A.; Ruas-Madiedo, P.; Galvez, J. Effect of a ropy exopolysaccharide-producing Bifidobacterium animalis subsp. lactis strain orally administered on DSS-induced colitis mice model. Front. Microbiol. 2016, 7, 868. [CrossRef] [PubMed]

22. Bai, Y.; Sun, E.N.; Shi, Y.D.; Jiang, Y.Y.; Chen, Y.; Liu, S.L.; Zhao, L.; Zhang, M.; Guo, H.Y.; Zhang, H.; et al. Complete genome sequence of Streptococcus thermophilus MN-BM-A01, a strain with high exopolysaccharides production. J. Biotechnol. 2016, 224, 45-46. [CrossRef] [PubMed]

23. Di Sabatino, A.; Biancheri, P.; Rovedatti, L.; MacDonald, T.T.; Corazza, G.R. Recent advances in understanding ulcerative colitis. Intern. Emerg. Med. 2012, 7, 103-111. [CrossRef] [PubMed]

24. Cui, Y.H.; Jiang, X.; Hao, M.Y.; Qu, X.J.; Hu, T. New advances in exopolysaccharides production of Streptococcus thermophilus. Arch. Microbiol. 2017, 199, 799-809. [CrossRef] [PubMed]

25. Vaningelgem, F.; Zamfir, M.; Mozzi, F.; Adriany, T.; Vancanneyt, M.; Swings, J.; De Vuyst, L. Biodiversity of exopolysaccharides produced by Streptococcus thermophilus strains is reflected in their production and their molecular and functional characteristics. Appl. Environ. Microb. 2004, 70, 900-912. [CrossRef]

26. Mozzi, F.; Vaningelgem, F.; Hebert, E.M.; Van der Meulen, R.; Moreno, M.R.F.; de Valdez, G.F.; De Vuyst, L. Diversity of heteropolysaccharide-producing lactic acid bacterium strains and their biopolymers. Appl. Environ. Microb. 2006, 72, 4431-4435. [CrossRef]

27. Broadbent, J.R.; McMahon, D.J.; Welker, D.L.; Oberg, C.J.; Moineau, S. Biochemistry, genetics, and applications of exopolysaccharide production in Streptococcus thermophilus: A review. J. Dairy Sci. 2003, 86, 407-423. [CrossRef]

28. Lemoine, J.; Chirat, F.; Wieruszeski, J.M.; Strecker, G.; Favre, N.; Neeser, J.R. Structural characterization of the exocellular polysaccharides produced by Streptococcus thermophilus SFi39 and SFi12. Appl. Environ. Microb. 1997, 63, 3512-3518.

29. Tokieda, S.; Komori, M.; Ishiguro, T.; Iwakura, Y.; Takahara, K.; Inaba, K. Dendritic cell immunoreceptor 1 alters neutrophil responses in the development of experimental colitis. BMC Immunol. 2015, 16, 64 . [CrossRef]

30. Da Silva, A.P.; Pollett, A.; Rittling, S.R.; Denhardt, D.T.; Sodek, J.; Zohar, R. Exacerbated tissue destruction in DSS-induced acute colitis of OPN-null mice is associated with downregulation of TNF-alpha expression and non-programmed cell death. J. Cell Physiol. 2006, 208, 629-639. [CrossRef] [PubMed]

31. Obermeier, F.; Kojouharoff, G.; Hans, W.; Scholmerich, J.; Gross, V.; Falk, W. Interferon-gamma (IFN-gamma)and tumour necrosis factor (TNF)-induced nitric oxide as toxic effector molecule in chronic dextran sulphate sodium (DSS)-induced colitis in mice. Clin. Exp. Immunol. 1999, 116, 238-245. [CrossRef]

32. Ito, R.; Shin-Ya, M.; Kishida, T.; Urano, A.; Takada, R.; Sakagami, J.; Imanishi, J.; Kita, M.; Ueda, Y.; Iwakura, Y.; et al. Interferon-gamma is causatively involved in experimental inflammatory bowel disease in mice. Clin. Exp. Immunol. 2006, 146, 330-338. [CrossRef] [PubMed]

33. Stevceva, L.; Pavli, P.; Husband, A.; Ramsay, A.; Doe, W.F. Dextran sulphate sodium-induced colitis is ameliorated in interleukin 4 deficient mice. Genes Immunity 2001, 2, 309-316. [CrossRef] [PubMed]

34. Dieleman, L.A.; Palmen, M.J.; Akol, H.; Bloemena, E.; Pena, A.S.; Meuwissen, S.G.; Van Rees, E.P. Chronic experimental colitis induced by dextran sulphate sodium (DSS) is characterized by Th1 and Th2 cytokines. Clin. Exp. Immunol. 1998, 114, 385-391. [CrossRef] [PubMed]

35. Chen, L.L.; Wang, X.H.; Cui, Y.; Lian, G.H.; Zhang, J.; Ouyang, C.H.; Lu, F.G. Therapeutic effects of four strains of probiotics on experimental colitis in mice. World J. Gastroenterol. 2009, 15, 321-327. [CrossRef] [PubMed]

36. Liu, Y.W.; Su, Y.W.; Ong, W.K.; Cheng, T.H.; Tsai, Y.C. Oral administration of Lactobacillus plantarum K68 ameliorates DSS-induced ulcerative colitis in BALB/c mice via the anti-inflammatory and immunomodulatory activities. Int. Immunopharmacol. 2011, 11, 2159-2166. [CrossRef] [PubMed]

37. Je, I.G.; Lee, D.G.; Jeong, D.G.; Hong, D.; Yoon, J.M.; Moon, J.S.; Park, S. The Probiotic, ID-JPL934, attenuates dextran sulfate sodium-induced colitis in mice through inhibition of proinflammatory cytokines expression. J. Med. Food 2018, 21, 858-865. [CrossRef] 
38. Pan, T.; Guo, H.Y.; Zhang, H.; Liu, A.P.; Wang, X.X.; Ren, F.Z. Oral administration of Lactobacillus paracasei alleviates clinical symptoms of colitis induced by dextran sulphate sodium salt in BALB/c mice. Benefic. Microbes 2014, 5, 315-322. [CrossRef]

39. Lee, S.H. Intestinal permeability regulation by tight junction: Implication on inflammatory bowel diseases. Intest. Res. 2015, 13, 11-18. [CrossRef]

40. Hermiston, M.L.; Gordon, J.I. Inflammatory bowel disease and adenomas in mice expressing a dominant negative N-cadherin. Science 1995, 270, 1203-1207. [CrossRef]

41. Devriese, S.; Eeckhaut, V.; Geirnaert, A.; Van den Bossche, L.; Hindryckx, P.; Van de Wiele, T.; Van Immerseel, F.; Ducatelle, R.; De Vos, M.; Laukens, D. Reduced mucosa-associated butyricicoccus activity in patients with ulcerative colitis correlates with aberrant claudin-1 Expression. J. Crohns Colitis 2017, 11, 229-236. [CrossRef] [PubMed]

42. Yamamoto-Furusho, J.K.; Mendivil-Rangel, E.J.; Fonseca-Camarillo, G. Differential expression of occludin in patients with ulcerative colitis and healthy controls. Inflamm. Bowel Dis. 2012, 18, e1999-e1999. [CrossRef] [PubMed]

43. Chang, J.; Leong, R.W.; Wasinger, V.C.; Ip, M.; Yang, M.; Phan, T.G. Impaired intestinal permeability contributes to ongoing bowel symptoms in patients with inflammatory bowel disease and mucosal healing. Gastroenterol. 2017, 153, 723-731. [CrossRef] [PubMed]

44. Merga, Y.; Campbell, B.J.; Rhodes, J.M. Mucosal barrier, bacteria and inflammatory bowel disease: Possibilities for therapy. Dig. Dis. 2014, 32, 475-483. [CrossRef]

45. Zhou, X.T.; Qi, W.C.; Hong, T.; Xiong, T.; Gong, D.M.; Xie, M.Y.; Nie, S.P. Exopolysaccharides from Lactobacillus plantarum NCU116 regulate intestinal barrier function via STAT3 signaling pathway. J. Agric. Food Chem. 2018, 66, 9719-9727. [CrossRef] [PubMed]

46. Zhang, J.; Cao, Y.; Wang, J.; Guo, X.; Zheng, Y.; Zhao, W.; Mei, X.; Guo, T.; Yang, Z. Physicochemical characteristics and bioactivities of the exopolysaccharide and its sulphated polymer from Streptococcus thermophilus GST-6. Carbohydr. Polym. 2016, 146, 368-375. [CrossRef]

47. Murthy, S.N.; Cooper, H.S.; Shim, H.; Shah, R.S.; Ibrahim, S.A.; Sedergran, D.J. Treatment of dextran sulfate sodium-induced murine colitis by intracolonic cyclosporin. Dig. Dis. Sci. 1993, 38, 1722-1734. [CrossRef]

Sample Availability: Not available.

(C) 2019 by the authors. Licensee MDPI, Basel, Switzerland. This article is an open access article distributed under the terms and conditions of the Creative Commons Attribution (CC BY) license (http:/ / creativecommons.org/licenses/by/4.0/). 